The Effect of CSR Evaluations on Affective Attachment to CSR in Different Identity

\title{
Orientation Firms
}

Barbara Fryzel (Corresponding Author)

Jagiellonian University, Faculty of Management and Social Communication,

Ul. Lojasiewicza 4, 30-348 Krakow, Poland

Tel: +48126645632

Email:barbara.fryzel@uj.edu.pl

Nina Seppala

Lincoln Business School, University of Lincoln, Brayford Pool, Lincoln, LN6 7TS UK

Tel: +44 (0)1522 835609

Email: nseppala@lincoln.ac.uk

\section{ACKNOWLEDGEMENTS}

This research was financed by The National Science Centre, Poland, decision no DEC2012/05/B/HS4/02505 


\title{
The Effect of CSR Evaluations on Affective Attachment to CSR in Different Identity Orientation Firms
}

\begin{abstract}
The goal of the present research is to examine the way in which organisational identity orientation and corporate social responsibility (CSR) interact to produce affective attachment and related beneficial behaviours among organisational members. Using a questionnaire administered in Poland, we show that when CSR activity is viewed as authentic by employees, it leads to affective attachment to the organisation's CSR stance, while an instrumental evaluation is correlated with a negative attachment to the CSR stance. The results suggest that CSR motives are particularly important for organisations with relational and collectivistic identity orientations because of the focus of these organisations on mutual or collective good that can be demonstrated through CSR. The results contribute to social identity literature by establishing a clear relationship between the concepts of identity orientation and CSR and showing that only authentic CSR produces affective attachment and behaviours that benefit the organisation.
\end{abstract}

Keywords: Corporate Social Responsibility; affective attachment; identity orientation; identity; CSR motives

\section{INTRODUCTION}

The authenticity of corporate social responsibility (CSR) activity has attracted growing attention as an issue that may affect how CSR is perceived (e.g., Ellen et al. 2006). Research in authenticity suggests that judgments about authenticity are informed by attributions 
assigned to CSR activities (Ellen et al. 2006), but it has remained unclear whether this mechanism applies to employee judgments as the concept of attributions was analysed in the context of external stakeholders. Employees are arguably in a better position than consumers and other external constituents to evaluate the motives behind CSR because of their tacit knowledge of the organisation.

If authenticity of CSR activity is viewed as important by employees, it may also affect their behaviours as organisational members. For example, it has been shown that employees' task performance depends on the intrinsic and extrinsic motives assigned to CSR (Story \& Neves 2015). This is particularly important in the context of managing social risks in companies operating globally because responsible conduct arguably depends on the commitment of employees to CSR as it is employees who make day-to-day operational decisions (Collier \& Esteban 2007).

We are interested in how CSR is viewed by employees in the context of different motives behind CSR activity and how this may influence how employees relate to the organisation. We employ Brickson's (2005) concept of organisational identity orientation to capture the way in which organisational members relate to their organization and its stakeholders. The concept has an inherent connection to the idea of CSR defined as the company's relationships to societal stakeholders (Clarkson 1995). By linking identity orientation to the concept of CSR, we build on and contribute to the literature in both identity theory and CSR.

\section{CONCEPTUAL BACKGROUND}




\subsection{Identity orientation and CSR motives}

The way in which businesses interact with the wider society can be framed and operationalised as stakeholder management (Clarkson 1995; Freeman 1984; Donaldson \& Preston 1995; Sen et al. 2006). Research carried out by Clarkson (1995) showed that managers conceptualise their role in society in terms of stakeholders rather than some more abstract social categories (Clarkson 1995). As a result, the stakeholder concept has been used in CSR literature to identify, assess and prioritise corporate connections and responsibilities in society. Viewed from this perspective, corporate responsibility pertains to how companies engage with their stakeholders.

A growing body of literature brings together the concepts of identity, stakeholders and CSR investigating the role and outcomes of identity in stakeholder relationships (Brickson 2005; Crane \& Ruebottom 2011; Scott \& Lane 2001; Sen et al. 2006). There is evidence to suggest that CSR actions reveal the identity of organisations and lead to positive attitudes towards an organisation as well as an intent to commit personal resources for the benefit of the organisation (Sen et al. 2006). Brickson's (2005) model of organisational identity orientation connects the concept of identity with the way in which an organisation relates to its stakeholders. As such, Brickson's model sheds light on how identity as experienced by organisational members shapes an organisation's relation to its stakeholders and, as a result, its role in society. Brickson's model therefore provides a unique link between the concepts of organisational identity, stakeholders and CSR.

Brickson's (2005) concept of organisational identity orientation is based on an empirical study of how organisational members collectively relate to their stakeholders. Brickson built 
on the work of Albert and Whetten (1985) who defined identity as the qualities that are most central, enduring, and distinctive for an organisation. Brickson viewed identity as shared beliefs among organisational members about the link between an organisation and its boundaries with others. As such, the model offers a way of conceptualising identity across organisations with a focus on how relations with stakeholders are reflected in the identity. Before Brickson's work, literature in the area of organisational identity had examined connections between identity and the organisation's strategic responses to issues arising from the organisational environment (Dutton \& Dukerich 1991), but stakeholders had not been integrated in analytical constructs.

Brickson (2005) referred to identity orientations as motivation states that influence relationship patterns with others. She defined identity orientation as a shared understanding among organisational members of the organisation's relation to others. Based on research in social psychology, she suggested that relations are either (i) individualistic (organisations as separate entities), (ii) relational (organisations as a set of dyadic relationships with specific others) or (iii) collectivistic (organisation as a part of a larger collective). An individualistic orientation is associated with a concern for organisational welfare and the focus is on traits that distinguish the organisation and separate it from others. A relational orientation is associated with an emphasis on the well-being of particular others and the organisation is seen by its members as sharing traits with particular other organisations including its clients. Finally, a collectivistic orientation is associated with a concern for the welfare of a greater collective. Accordingly, the organisation is characterised by the traits it shares with a larger community. Brickson found that different identity orientations can co-occur within one organisation, but the type of organisation and its clients make certain orientations more likely. For example, organisations serving the public sector tend to be more collectivistic. 
CSR has been defined in relation to how an organization deals with its stakeholders (Clarkson 1995). However, relationships to stakeholders are only one aspect of how CSR is interpreted by organisational members and consumers. Empirical research shows that other aspects include organisational values and organisational culture (Kim \& Kim 2010; Lee et al. 2013). The concepts of CSR and identity orientation are therefore separate concepts that can be studied independently to explore their interactions.

According to Brickson, it is employees who collectively create an organisation's identity orientation through their perceptions of how the organisation relates to its stakeholders and how organisational welfare is created. Employees also hold views about the authenticity of the organisation's approach to CSR. As defined by McShane and Cunningham (2012), authenticity refers to the consistency of internal behaviours and values with the external message sent to the market. Employees make judgments about the authenticity of CSR on the basis of their experiences and interaction internally and with outside stakeholders. There is hence a connection between identity orientation and CSR motives as perceived by employees because both concepts pertain to the role of companies in society.

Previous research has showed that there is cynicism about the motives behind CSR activity (Aquevene \& Encina 2010). While there are organisations that are seen to pursue CSR for the purpose of playing a positive role in society, there are also organisations engaging in CSR for instrumental reasons, including protecting against reputational damage and increasing sales through social marketing (Ellen et al. 2006; Graafland \& van de Ven 2006). For example, the analysis of companies adopting the Global Compact principles show that economic gains and image enhancement remain the main motives for joining the Global Compact (Arevalo et al. 
2013).

There is an inherent connection between identity orientation and the motivation behind CSR activity. On the one hand, when organisational identity orientation is individualistic and therefore focused on the self-interest of the organisation, employees will view the company's CSR activity as instrumentally motivated. On the other hand, when identity orientation is relational or collectivist and the organisation is viewed as inherently linked to particular stakeholders or the community at large, CSR activity will be viewed as authentic because there is a consistency between the identity orientation and CSR activity that enhances the welfare of the larger whole of which the organisation is a part of.

Moreover, there is an inherent connection between Brickson's (2005) relational and collectivistic identities and the notion of CSR and this is why the organisation's CSR motives are seen as authentic. Brickson defined a relational orientation as an emphasis on the wellbeing of particular partners and the maintenance of relationships to these partners because organisational members view the organisation through dyadic relations to the partners. A collectivistic orientation is associated with a concern for the welfare of a larger group and the organisation is viewed by its members as part of a larger collective. In both cases, organisational welfare is seen as being dependent on others, whether particular partners or a larger group. The organisation is therefore viewed larger than its actual boundaries and its responsibilities extend to other members of the society. From this follows that the motivation behind CSR activity is viewed as an authentic part of how the organisation interacts with stakeholders whose well-being is connected to the organisation's own welfare. 
that employees who perceive their firm's identity orientation as individualistic view the firm's CSR activity as instrumentally motivated, while employees who perceive their firm's identity orientation as relational or collectivistic view the firm's CSR activity as authentic.

\subsection{Identity orientation and affective attachment}

Identity orientation is not only connected to views about the authenticity or instrumental nature of the company's CSR stance, identity orientation is also connected to the level of affective attachment organisational members feel towards the CSR stance. Affective attachment to a group is distinct from a mere awareness of belonging to a group (Ellemers et al. 1999). Organisational members may be cognitively aware of a group membership, but they may not feel emotionally engaged with the group. For example, we may consider ourselves as part of our work team and wear signals of this membership including uniforms without feeling an emotional connection to the team. In this context, affective attachment refers to the emotional significance given to a group membership (Allen \& Meyer 1990; Tajfel 1978). Affective attachment is often studied as a dimension of social or organisational identity in addition to the dimensions of cognitive awareness of group membership and positive or negative connotations related to that membership (Ellemers et al. 1999; Tajfel \& Turner 1979). The extent of affective commitment to a group partially explains why people in the same social group can show different attitudes and behaviours including levels of job performance, turnover, and absenteeism (Branscombe \& Wann 1994; Ellemers \& Van Rijswijk 1997).

Researchers have previously found that affective attachment is enhanced by diverse factors including organisational support (Rhoades et al. 2000), base pay level (Kuvaas 2006) and age 
(Allen \& Meyer 1993). Among other factors, CSR can enhance affective attachment to the organisation. Collier and Esteban (2007) argued that attachment to CSR is more likely when CSR fosters the alignment of employee and organizational identities. Furthermore, Brammer, Millington and Rayton (2007) discovered that external CSR is positively related to organisational commitment and this commitment is as strong as job satisfaction although the results are affected by employee gender. Employees who perceive their organisation's identity orientation as relational or collectivistic become emotionally attached to the organisation's CSR stance because CSR is a way to communicate and demonstrate the company's commitment to the community and other stakeholders. As argued by Brickson (2005), relational and collective identity orientations involve the positioning of the organisation in relation to either particular stakeholder groups or the community as a whole. Through CSR, organisations can communicate this concern for others and their welfare. CSR can also increase a sense of pride and status which have been found to have a positive impact on affective attachment (Ellemers et al. 2011).

In contrast, employees who view the identity orientation of their organisation as individualistic do not experience increases in levels of affective attachment to the organisation's CSR stance because the organisation is not seen as inherently linked to any particular stakeholders or the society at large. Because of this individualistic approach, the role CSR plays in strengthening links to stakeholders is not seen as important for the organisation.

Hypothesis 2: Firms identity orientation relates to affective attachment to CSR in such way that employees who perceive their organisation's identity orientation as relational or collectivistic are more emotionally attached to the organisation's CSR stance 
than those who view the identity orientation as individualistic.

\subsection{CSR motives influence affective attachment}

Our final pair of hypothesis relates to the motives underpinning CSR activity and how these motives relate to affective attachment. The motives are especially important in collectivist and relational identity organisations where CSR needs to be genuine to create affective attachment. The motives behind CSR activity are therefore important for employees and other organisational stakeholders. Motives that are viewed as genuine or authentic generate affective attachment towards the company's CSR activity, while instrumental motives have a negative effect on affective attachment. As seen above, affective attachment is related to various organisational and individual outcomes including employee morale and job satisfaction (Ellemers et al. 1999).

Employees care about the authenticity of CSR because it contributes to their self-image and pride (McShane \& Cunningham 2012). Views about the organisation's CSR activity have an impact on the perceived morality of the organisation with a consequent effect on individual pride and affective commitment (Ellemers et al. 2011). Research shows that employee motivation can be enhanced more by pride and affective commitment than by pay (Branscombe et al. 2002; Tyler \& Blader 2000). Pride is also connected to other beneficial outcomes for the organisation including job satisfaction (Smith \& Tyler 1997; Tyler \& Blader 2000). It can hence be argued that CSR activity that is motivated by a genuine effort to contribute to the society creates affective attachment towards the organisation's CSR stance.

In contrast, CSR activity that is viewed as an instrument for financial performance and other organisational goals instead of a societal benefit does not generate affective attachment 
among employees. Maignan (2001) showed in her research that organisational members do not consider economic and profit-seeking activity as CSR even though this activity may be considered as the primary role of economic actors in society. In effect, there seems to be an increasingly negative response to CSR activity that is seen to be motivated by profit (Cho \& Hong 2009).

Hypothesis 3: Evaluation of CSR motives relates to affective attachment to CSR in such way that authentic CSR motives increase affective attachment to CSR activity, while instrumental CSR motives decrease affective attachment to CSR activity.

Hypothesis 4: Evaluation of CSR motives will mediate the relation between firm's identity orientation and affective attachment to CSR.

Figure 1 presents the model of hypothesised relationships. Accordingly, companies with collectivistic and relational identity orientations evoke affective attachment among their employees by engaging in CSR for authentic rather than instrumental reasons. CSR activity and the motivations underpinning it are less important for individualistic organisations where CSR does not create similar affective attachment and related benefits. 
Figure 1. Summary of hypotheses

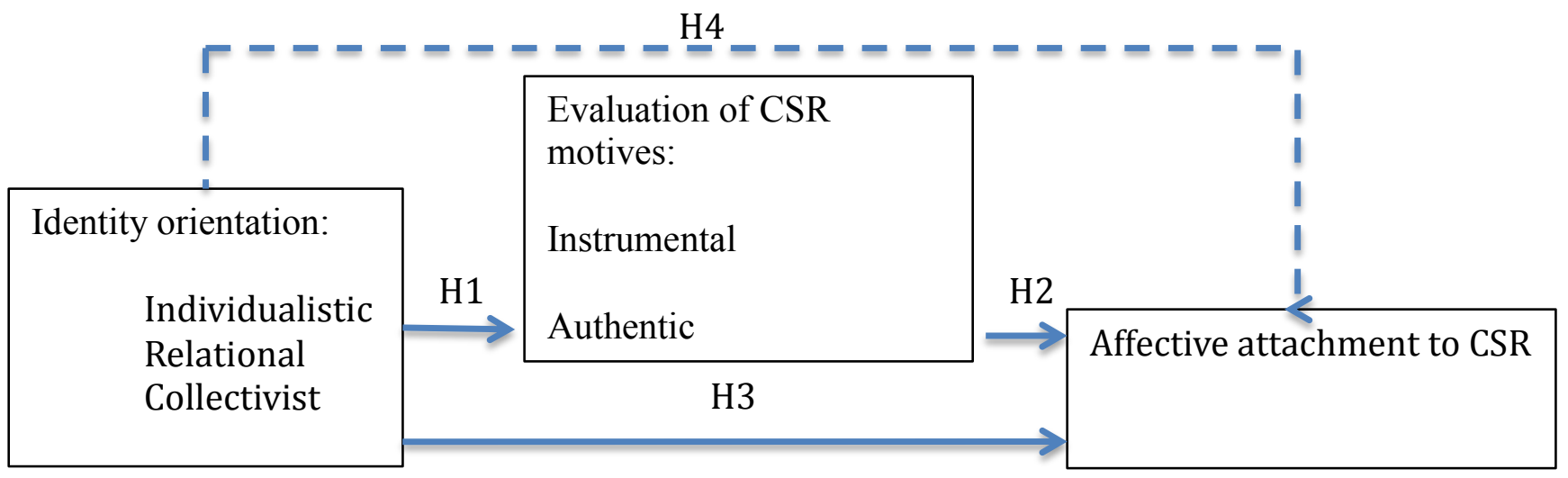

\section{METHODOLOGY}

\subsection{Pilot study}

We conducted a qualitative pilot study in order to obtain unrestricted interpretations from employees regarding the CSR stance of their organisation. The pilot study was also intended generate questionnaire items for the main survey. We used interviews to ask organisational members to give their assessment of how their firms approached CSR. The interview questions were designed on the basis of Albert and Whetten's (1985) definition of organisational identity as important features that distinguish an organisation from others over time. We asked the interviewees to comment on whether they thought their firm displayed any distinctive, enduring and central characteristics as far as CSR was concerned. The interviewees were also asked to give examples of a threatening situation following Brickson's (2005) methodology.

Interviews were first performed with a group of nine executives with an average age of 44 years. The majority of the interviewees had worked for their current company for more than four years with fairly large teams of a minimum of 50 people. The executives were 
approached through the alumni and MBA associations of the Krakow University of Economics. They received an email invitation for the study and the subsequent interviews were conducted over the phone. The first interviews were followed by another 31 interviews of executive students taking classes at the Jagiellonian University in Poland. This second sample was composed of interviewees with work experience between 6 months and 4 years. Only 24 interviews from this group were included in the final analysis because of omissions and lack of answers. We used the concept of saturation as discussed by McShane and Cunningham (2012) to determine a satisfactory number of interviews. Saturation is the point at which no additional concepts or relationships among concepts emerge (Guest et al. 2006). Saturation has been previously established at the level of twelve interviews (Guest et al. 2006) and 44 interviews (Beckman et al. 2009). The average age among the respondents in the second group was 24 years with $58.3 \%$ of the sample having worked for their current firm for less than one year and $71.4 \%$ working for retail or professional services. By designing the pilot sample to include expert executives and executive students, we wanted to capture perceptions and attitudes across employees with various levels of tenure in organisations and with different status.

We used QSR NVivo software to analyse the data. Four categories emerged from a frequency analysis of the interview material: (1) benefits for the company (31.82\%), (2) profits and quality (13.64\%), (3) stakeholder relationships and honesty (36.36\%), and (4) fair play, consistency, development and help (18.15\%). After analysing the four categories and associated interview material further, we combined the first two categories and labelled them as an instrumental approach to CSR $(45.46 \%)$. The other two categories were also merged and labelled as an authentic approach to CSR (54.51\%). A direct quote from one of the interviewees explains the difference between an instrumental and authentic approach in a 
succinct way: 'There are firms who do it because it is fashionable and attractive in a marketing sense and there are those who do it because they truly want to help the society'. The pilot study findings are summarised in Table 1 .

- Table 1 about here -

The category of instrumental approaches to CSR consisted of references to CSR as something that was beneficial for the company, although the respondents were not always specific about the nature of the benefits. In general, the motivation behind CSR was seen as instrumental rather than based on values or a certain ethical point of view. The instrumental category involved some direct references to profits, quick income, and reputation indicating that the adoption of CSR would bring financial and other benefits for the organisation. For example, one interviewee commented: '[...] the company uses CSR to create a good image' and '[...] undertakes CSR only because it generates benefits such as good reputation, publicity and word of mouth'. Another employee of a small firm in the executive training industry said: 'I have mixed feelings towards CSR. I have seen many times that firms get engaged in that kind of activity only when it is trendy and in order to get listed in some rankings, while in reality one should approach CSR (...) in a genuine manner.'

The authentic category of approaches to CSR was constructed from references to honesty and values as a basis of stakeholder relationships. Fair play, norms, building trust, helping the society, and consistency were also considered important for an authentic approach to CSR. For example, one interviewee described their company's approach to CSR as authentic in reference to fairness and focus on employee wellbeing. Overall, the interviewees viewed support and understanding of employees as important, although they were of the view that 
honesty should be enforced through rules, thus 'making cheating more difficult'. Some interviewees linked CSR to product quality: 'diligent and centered on the responsibility for the quality of the products'. Finally, values were seen as important for CSR: 'We try to adhere to the ethical values that are quite obvious and agreed by everyone in Western civilization'.

\subsection{Main survey and the measures}

In spite of limitations relating to generalisability, we used a convenience sample, following the views of Calder et al. (1981, 1982). While convenience sampling increases internal validity, it limits the generalisability of findings, although the need for generalizability in research designed to test theory rather than to design interventions has been questioned (Calder et al. 1981, 1982). 'Theories are stated at a universal level. As long as a sample is relevant to the universe of the theory, it constitutes a test of that theory' (Calder et al. 1982, p. 241). Nevertheless, because of the abovementioned reservations, the results should be interpreted with caution.

We administered the survey to a sample of 131 respondents taking an executive education course in a Polish university. The survey was conducted over two days during the course. The respondents had worked for their current company from 6 months to 4 years. The sample included respondents from multiple sectors including retail $(24.4 \%)$, banking and finance (12.9\%), and IT and communications $(12.2 \%)$. The majority $(50.39 \%)$ had no people management responsibility and $36 \%$ of the respondents had less than 10 people in their team. Finally, $43 \%$ of the respondents worked for mid-size firms with less than 250 employees and 
another $21.7 \%$ worked for small firms employing less than 10 people.

To reduce the common method bias inherent to survey-based research, we followed procedural remedies as suggested by Podsakoff (2003). Given the nature of the relationships measured, we were not able to separate the source of data for predictor versus criterion variables. Instead, we sought to avoid social desirability bias by informing the respondents that we were interested in all opinions irrespectively of whether they were positive or negative. We described the research goal as an attempt to understand business and individual attitudes towards CSR, thus making a link between identification types and CSR attitudes less explicit. Regarding scales construction, we used a mix of items developed from the pilot study and existing scales which were back-to-back translated from English to Polish. To facilitate responses to multi-item scales, we used verbal labels instead of numbers. Finally, all respondents were ensured anonymity.

As will be explained in detail below, the pilot study results were used to develop the CSR evaluation scale, while existing measures were adopted for measuring affective attachment and identity orientation. In addition, several control variables were included in the questionnaire. Previous research has shown that organisational tenure increases identification (Hall \& Schneider 1972; Mael \& Ashforth 1992) because tenure in a social group relates to self-categorisation (Kramer 1991). We thus included organisational membership as a control variable, operationalised as the number of years employed by the current organisation (less than a year, 1-3 years, $4-10$ years, more than 10 years).

Moreover, previous research has shown that leadership and organisational commitment are connected (see Avolio et al. 2004 for a review). Also, the role of leaders has been shown to be 
significant in building identities (Clark et al. 2010). Waldman et al. (2006), in their neocharismatic conceptualization of leadership, argued that inspiring of others happens through values and emotional appeal. Specifically, leaders articulate visions that are based on ideology, values and imagery generating a high degree of confidence and motivation among followers (Waldman et al. 2006). '(...) top-level managers are obviously in a position to influence (...) strategies' (Waldman and Siegel, 2008, p.118). We therefore assumed that having a direct responsibility for constructing a coherent identity in teams may influence the commitment of leaders to the values they transmit. Also, leading by example may foster the leader's attachment to the organisation. We assumed such leadership to be present among managers and thus included managerial responsibility as another control variable, operationalised as the number of team members $(1-3,4-10,11-100$ or more than 100 people). The respondents also had the option of 'not applicable' in the case they were working as specialists without any direct team responsibilities.

\subsubsection{Authentic and instrumental evaluation of CSR}

CSR evaluation was measured using items developed from the pilot study. Two questions were used to measure authentic evaluation ('In my organization, responsibility towards the society is taken seriously', 'Our corporate social responsibility activities are genuine'). The items showed a good level of consistency with a Cronbach's alpha of 0.72 and SpearmanBrown split-half reliability of 0.73 . Another four questions were designed to measure instrumental evaluation to ensure that all the connotations raised by pilot study participants were included and to enhance the reliability of the scale ('Our approach to business ethics and responsibility is profit-driven', 'In my organization, corporate social responsibility is a marketing tool', 'Our corporate social responsibility activities are self-interested rather than 
beneficial for society', 'Business ethics is rarely seen as fundamental at my company'). The instrumental evaluation scale had a Cronbach's alpha at the level of 0.67. Even though the alpha was below 0.7, a generally accepted level of reliability (Nunally 1978), we accepted the result on the basis of the argument that the levels of acceptable Cronbach's alpha depend on whether items are used in exploratory studies as in our case or for more general research purposes when the levels are expected to be higher (Lance et al. 2006; Henson 2001).

\subsubsection{Affective attachment to CSR}

The scale to measure affective attachment was adopted from Meyer, Allen and Smith (1993) and their study of occupational attachment. Meyer, Allen and Smith developed the scale from a three dimensional measure (Meyer et al. 1990) and confirmed in further studies that it can be used to assess attachment to organisations and other entities. The scales have been evoked to research attitudes towards organisations (Shore, Barksdale \&Shore, 1995) and emotional commitment to professions (Meyer et al. 1993). We adapted Likert-items developed by Meyer, Allen and Smith (1993) by relating their wording to the measurement of attachment to CSR rather than to an organisation. For example, 'This organisation has a lot of personal meaning for me' was changed to 'The socially responsible activities my company takes have a lot of personal meaning to me'. Other items adapted for the study included: 'My organisation's approach to corporate social responsibility is the same as my own', 'My company's approach to business ethics is important to my self-image', 'I regret the way we deal with business ethics in my company' (R), 'I am proud of the corporate social responsibility activities my company undertakes', and 'I do not personally care about my company's policy in corporate social responsibility' (R). The scale showed high internal consistency with a Cronbach's alpha of 0.82 and Spearman-Brown split-half reliability of 
0.86.

\subsubsection{Identity orientation}

To measure identity orientation we used Brickson's (2005) three multiple choice questions representing the three identity orientations. However, we decided to treat the items as separate qualitative issues rather than a scale due to the nature of the statements which do not suggest that they belong to any unidimensional construct. This decision was confirmed by the reliability analysis. The questions were: 'My organisation views itself primarily as: (i) distinct and standing apart from other organisations, (ii) a good partner to those with whom it interacts, or (iii) a good member to a larger community'; 'What is most important to my organisation is: (i) working to improve the welfare of particular others with whom the organisation has significant and gratifying relationships, (ii) working to improve the welfare of community it values and belongs to, or (iii) working to promote and maintain its own welfare'; 'My organisation is most concerned about: (i) its relationship with a greater community it values and belongs to, (ii) its distinctiveness from other organisations, or (iii) its relationships with particular others whose welfare it values'. Items concerning the answers for each multi-item question were summed up to make three scales with a possible range from 0 to 3 thus constructing the identity scale used in the research. Relatively low Cronbach's alphas of the identity orientation scales $(0.39-0.50)$ suggested that the items might be somewhat heterogeneous. However, instrumental reliability depends largely on the amount of items, so considering that there were only three items in the scale and the reliability was low, the results for the scale should be treated with caution. In spite of the low reliability of the identity scale, many significant results were obtained indicating that had the reliability been higher, the obtained effects would have been even higher. 


\section{RESULTS}

The analysis of correlations between the main variables is summarised in Table 2. Affective attachment to CSR is strongly and positively related to authentic evaluation of CSR motives and negatively related to instrumental evaluation. Individualistic identity orientation is negatively related to affective attachment and authentic evaluation of CSR motives. Collectivist identity orientation relates positively both to affective attachment and authentic CSR evaluation and negatively to instrumental CSR evaluation.

- Table 2 about here -

We performed two stepwise multiple regression analyses to verify Hypothesis 1, using first instrumental evaluation of CSR and then authentic evaluation of CSR as the dependent variables. In both cases, identity orientation types, i.e. individualistic, relational and collectivistic identity orientation served as the predictors. We used length of employment and managerial responsibility as control variables in the analysis.

The results of the regression analysis showed that collectivist identity orientation was a significant predictor for instrumental CSR explaining $12 \%$ of the variance in the dependent variable. Control variables were not significant. Both individualist identity orientation and collectivist identity orientation were significant predictors for authentic CSR evaluation. Taken together, they explained $28 \%$ of the variance in the dependent variable. Individualist identity orientation showed a negative relationship with authentic evaluation, while collectivist identity showed a positive one, thus providing support for Hypothesis 1. 
To study Hypothesis 2, we run regression analysis with the three subscales for identity orientation as predictors and affective attachment to CSR as a dependent variable. As previously, length of employment and managerial responsibility were included as control variables. Both the collectivist and individualist identity orientation proved significant as predictors of affective attachment to CSR, explaining $46 \%$ of variance. Collectivist identity orientation was a positive predictor of affective attachment to CSR, while individualistic identity orientation was a negative one, thus supporting Hypothesis 2.

In order to investigate Hypothesis 3, we run a stepwise regression analysis with affective attachment to CSR as a dependent variable and authentic and instrumental CSR evaluation as predictor variables. As previously, length of employment and managerial responsibility were entered as control variables. The regression analysis showed that authentic CSR evaluation was a significant predictor for affective attachment to CSR explaining $44 \%$ of variance. As a positive predictor, Hypothesis 3 was partially supported. No significant association was found between instrumental CSR evaluation and attachment to CSR.

- Table 3 about here -

Given that identity orientation relates to CSR evaluation, which in turn relates to affective attachment, we used a mediation model to see whether CSR evaluation mediated the relation between identity orientation and affective attachment. Identity orientation was computed as the independent variable, evaluation of CSR motives as the mediator, and affective attachment as the dependent variable. We run a series of analyses, applying 95\% confidence intervals using bootstrapping. The mediation effect is considered significant when the 
confidence interval does not include 0 (Preacher \& Hayes 2004). The results are presented in Table 4. The existence of the mediation can only be inferred from the bootstrap generated confidence intervals, not from the significance of the indirect effect of the predictor on the dependent variable, controlled for the mediator (Preacher \& Hayes 2004).

- $\quad$ Table 4 about here -

Out of six mediation analyses computed, three yielded statistically significant results in relation to the confidence intervals. In the first significant mediation, collectivist identity orientation was negatively related to instrumental evaluation, while instrumental evaluation related negatively to affective attachment to CSR. As for the second mediation effect, individualistic identity orientation was negatively related to authentic evaluation, which related positively to affective attachment. In the third mediation effect, collectivistic identity orientation was positively related to authentic evaluation, which related positively to affective attachment. In summary, collectivist identity orientation increased affective attachment to CSR through the increase of authentic evaluation and decrease of instrumental evaluation. At the same time, individualist identity orientation decreased affective attachment through a decrease of authentic evaluation of CSR motives. These results provide support for Hypothesis 4 according to which evaluation of CSR motives mediates the relation between identity orientation and affective attachment.

\section{DISCUSSION}

Our results show that there is a relationship between CSR motives and organisational identity 
orientation. More specifically, instrumentally motivated CSR is connected to individualistic identity orientation, while authentic CSR is related to relational and collectivistic identity orientation. Furthermore, the results suggest that authentic CSR explains a large proportion of variation in affective attachment to the organisation's CSR stance, which in turn is positively correlated with relational and collectivistic identity orientations. The connection between affective attachment and identity orientation seems therefore to be facilitated by the evaluation of CSR motives.

The results contribute to Brickson's (2005) identity orientation model by showing that firms generate affective attachment among employees by engaging in CSR for genuine rather than instrumental reasons. Such affective attachment is particularly important for organisations with relational or collectivist identity orientations because of the positive relationship between authentic CSR and these orientations, and the benefits that affective attachment generally brings including employee morale and job satisfaction (Ellemers et al. 1999). The results of our research therefore show how identity orientation, CSR, and employees as stakeholders can be interlinked and produce employee commitment that enforces the organisation's relationship to its environment as well as its performance through beneficial employee behaviours resulting from alignment between identity orientation and CSR motives. Such a link between identity orientation and CSR was inherent in Brickson's work, but our results have made it explicit and showed the importance of affective attachment in facilitating the link.

Affective attachment has often been studied as part of the social identity and organisational identity concepts (Tajfel \& Turner 1979; Ellemers et al. 1999). Tajfel (1978) defined social identity as ' $(. .$.$) that part of an individual's self- concept which derives from his knowledge of$ 
his membership of a social group (or groups) together with the value and emotional significance attached to that membership'. Affective attachment has also been examined in the context of identification with companies. For example, CSR programmes have been found to increase identification leading to greater motivation and productivity (Berger et al. 2006). Our results demonstrate that affective attachment to CSR is only strengthened in certain conditions pertaining to the organisation's identity orientation and CSR motives. If affective attachment is essential for identity as suggested by Tajfel (1978), CSR pursued for genuine motivations can lead to stronger social and organisational identities in relational and collectivistic organisations. Based on previous literature, this in turn can enhance job performance and satisfaction (Margolish \& Walsh 2003; McShane \& Cunningham 2012).

Furthermore, the results of our research contribute to a better understanding of how cynicism about CSR (Aquevene \& Encina 2010) can be tackled. Our empirical results show that employees have clear views about the motivations underpinning CSR activity and these views influence their affective attachment to their organisation's CSR stance, especially in relational and collectivistic organisations. Indeed, our results suggest that organisations may not benefit from communicating about instrumentally motivated CSR to organisational members who are in a position to form judgements about the authenticity of CSR activity. Conversely, the results indicate how organisations can realise the benefits arising from CSR activity, an area of research that has been indicated as needing further development (e.g. Du et al. 2010; Lapeyre 2013; Sen et al. 2006). Our research suggests that communication about the organisation's CSR stance is essential for activating the benefits from an authentic approach to CSR so that employees are aware of the motives underpinning an organisation's CSR stance. Previous research has shown that CSR communication plays a role in building stakeholder dialogue (Johanssen \& Nielsen 2011) and corporate identity (Bravo et al. 2012). 
It has been argued that ' $(\ldots)$ most organisations disclose CSR information to construct communicated identities and legitimate behaviours' (Bravo et al. 2012). Our research supports this line of argumentation by showing that it is beneficial for organisations with a relational or collectivistic identity orientation to let their employees know about their genuine motivations behind CSR. Indeed, alignment between identity orientation and CSR motivations enhances affective attachment and related behaviours among employees. This conclusion is in line with earlier research showing that the role of CSR communication is important in fostering member identification (Morsing 2006).

\subsection{Limitations and future research}

Our study is not free of limitations. First, only one of Brickson's three identity orientation measures correlated with CSR evaluations and affective attachment. Brickson (2005) showed that her three multiple-item measures reflect a coherent construct of identity orientation, therefore we would expect that all three would show a similar pattern of significant correlations. However, the only measure which returned significant results was the one asking 'What is most important for my organization', while the other two ('My organization views itself primarily as...' and 'My organization is most concerned about...') remained statistically insignificant. One of the reasons for this could be a potential relation between identity orientations and national identity. Given that our research is based on a different national sample from the one used by Brickson, it would be worth exploring whether national identity affects construct consistency. Another possible explanation relates to semantic issues; while the original English wording of the measures allows for a clear distinction between various aspects of identity orientation, the same questions in Polish have a more synonymous 
meaning, which might make it more challenging for the respondents to see the subtleties of different identity aspects.

Second, our study is based on the concept of identity orientation and it measures the perceptions of employees constructed directly from the firms' attributes. However, identity orientation can also be measured on the basis of company image constructed through perceived external prestige (Herrbach \& Mignonac 2004) which is culture sensitive (Kim et al. 2010). Specifically, people from collectivist versus individualist cultures may have different perspectives due to different self-construal processes, i.e. people from highly collectivist cultures are motivated to conform to social norms (Morling et al. 2002). In individualist cultures, identities are largely independent and therefore related to internal attributes rather than to those pertaining to a given culture or society (Aaker \& Williams 1998). One of the possible lines of future research could be to explore how the relation between identity orientations, CSR evaluations and affective attachment to CSR changes if employees derive their conclusions on identity orientations on the basis of external stakeholder perceptions. Such research could be performed by using experiments, following examples such as Branscombe, Spears, Ellemers, \& Doosje (2002) where group pride was examined. Furthermore, it would be interesting to see how this relation changes in a multicultural environment. Such future work would improve our attempt to link macro- and micro-level issues, i.e. the connection between collective identities and individual behaviour by employing multi-level analysis and different sources of data.

Third, CSR attitudes and perceptions have been studied previously in the context of national differences and religious denominations (Brammer et al. 2007). They are contingent on cultural values and the views relating to the role of business in society (Kim \& Kim 2010) and 
leadership styles (Groves \& LaRocca 2011). Future research could explore whether the relation between identity orientation, affective attachment to CSR, and evaluation of CSR motives holds across different cultures, sets of values or leadership styles.

Finally, research by McShane and Cunningham (2012) suggests that personal characteristics may mediate the relationship between evaluation of CSR motives and affective attachment. Accordingly, emotional engagement at individual level to CSR may interact with perceptions of whether CSR is authentic or instrumental. For example, people who have an emotional commitment to local community issues may perceive community initiatives as more authentic than other CSR initiatives. Russell and Russell (2010) demonstrated through their study that a relationship exists between individuals who are concerned about global versus local issues and behavioural outcomes including purchasing intent depending on whether CSR communication concerns global or local issues. Another line of future research could identify which types of CSR evoke the greatest degree of affective attachment and how this outcome can be achieved.

\subsection{Practical implications}

At a more practical level, it is useful for managers to know when an organisation's approach to CSR is particularly important for its employees as this enhances employee behaviours that benefit the organisation. The results of our study suggest that companies should promote their CSR activity for internal audiences only when CSR is not linked to profit-seeking or other instrumental motives. The impact of CSR motives on affective attachment and identity orientations shows the importance of CSR communication through which employees can be made aware of CSR motives. The results therefore support the argument made by Ter Hoeven 
and Verhoeven (2011) according to which firms can increase affective commitment among employees through enhancing employee awareness of CSR. Our results however suggest that any communication of CSR should be genuine and it will only be effective when CSR is pursued for authentic motives. When CSR is motivated by instrumental drivers including, for example, an attempt to enhance the firm's reputation, it does not generate affective attachment. In order to demonstrate the authentic nature of the organisation's approach to CSR, managers should consider employees as a distinct stakeholder group that should be kept engaged and informed about policies and activities.

Moreover, managers should not use resources to communicate about the organisation's CSR activity when the organisation's identity orientation is seen as individualistic. The results of our study show that the way in which CSR motives are evaluated depends not only on specific types of CSR actions as suggested by researchers (Groza et al. 2011), but also on organisational identity orientation. This could mean that even when an organisation pursues well designed, proactive CSR activities, they could have no positive effects among employees if the identity orientation is seen as individualistic. In this situation, communication about CSR does not enhance affective attachment among employees and resources are better used elsewhere.

The managerial challenge in using communication and other tools to influence affective attachment to CSR pertains to the connection of the attachment to both individual and organisational characteristics. Affective attachment may be a result of the individual cognitive process of evaluating the organisation's CSR policy and activity as well as the organisation's relationship to its stakeholders and the society at large, i.e. its identity orientation. From this follows that managers, working to strengthen affective attachment in their teams, need to 
navigate between controlling how perceptions of authenticity and instrumentality are shaped and understanding the context of firm's relations to stakeholders and the society.

In order to juggle the challenge of influencing how CSR is perceived and being aware of the organisation's identity orientation, managers can use a range of tools. First, because individual evaluations can have a cognitive background, it is important to provide the rationale and full information around the organisation's CSR activity. For example, when new CSR initiatives are launched, employees should be informed and involved in the activity so that they are aware of the motivations behind the activity and the genuineness of key decision-makers. Managers can also use external means including CSR rankings and prizes to give more credibility and to legitimise the firm's CSR approach. Because evaluations may be subject to emotions as well as more rational analysis, managers will also need to think about charging communication about CSR emotionally. Furthermore, because different people react differently to different CSR initiatives (Russell and Russell 2010), managers should be aware and adjust communication accordingly. For example, cosmopolitans may not care about local community initiatives (ibid.).

Finally, in order to strengthen identity orientation as well as awareness of motivations behind CSR activity, managers can enhance affective attachment through consolidation and fostering the network of the organisation's stakeholder relations. For example, employees can be recognised through financial and non-financial schemes for improving relations to particular stakeholder groups in order to boost relational and collectivist identities. Moreover, employees can be encouraged to suggest ways in which they and the organization can contribute to society and this can be formally rewarded.

To summarise, it is not only communication about CSR that is important, but also the way in 
which CSR is designed including the involvement of employees and other stakeholders in the design and delivery of CSR activity. In addition, normal relations to stakeholders and their role in employee appraisal and reward schemes can enhance clarity of the organisation's relational or collectivistic identity and therefore affective attachment to CSR.

\section{REFERENCES}

Aaker, J. L., and Williams, P. 1998. 'Empathy versus pride: The influence of emotional appeals across cultures' Journal of Consumer Research, 25(3), 241-261.

Albert, S., and Whetten, D.A. 1985. 'Organizational identity'. In L. L. Cummings \& B. M. Shaw (Eds.), Research in Organizational Behavior, 17, 263-295. Greenwich, CT: JAI.

Allen, N. J., and Meyer, J. P. 1993. 'Organizational commitment: Evidence of career stage effects?' Journal of Business Research, 26(1), 49-61.

Arevalo, J. A., Aravind, D., Ayuso, S. and Roca, M. 2013. 'The Global Compact: an analysis of the motivations of adoption in the Spanish context' Business Ethics: A European Review, 22(1), 1-15.

Aquevene, C., and Encina, C. 2010. 'Corporate behavior, social cynicism, and their effect on individuals' perceptions of the company'. Journal of Business Ethics, 91(2), 311-324.

Avolio, B. J., Zhu, W., Koh, W., and Bhatia, P. 2004. 'Transformational leadership and organizational commitment: Mediating role of psychological empowerment and moderating 
role of structural distance'. Journal of Organizational Behavior, 25(8), 951-968.

Baron, R. M., and Kenny, D. A. (1986). 'The moderator-mediator variable distinction in social psychological research: Conceptual, strategic, and statistical considerations'. Journal of Personality and Social Psychology, 51, 1173-1182.

Beckman, T., Colwell, A., and Cunningham, P. H. 2009. 'The emergence of corporate social responsibility in Chile: The importance of authenticity and social networks'. Journal of Business Ethics, 86,191-206.

Berger, I. E., Cunningham, P. M., and Drumwright, M. E. 2006. 'Identity identification and relationship through social alliances'. Journal of the Academy of Marketing Sciences, 34, $128-137$.

Brammer, S., Millington, A. and Rayton, B. 2007. 'The contribution of corporate social responsibility to organizational commitment'. The International Journal of Human Resource Management 18(10), 1701-1719.

Brammer, S., Williams, G., and Zinkin, J. 2007. 'Religion and attitudes to corporate social responsibility in a large cross-country sample'. Journal of Business Ethics, 71(3), 229-243.

Branscombe, N. R., and Wann, D. L. 1994. 'Collective self esteem consequences of outgroup derogation when a valued social identity is on trial'. European Journal of Social Psychology, 24(6): 641-657. 
Branscombe, N. R., Spears, R., Ellemers, N., and Doosje, B. 2002. 'Intragroup and intergroup evaluation effects on group behavior'. Personality and Social Psychology Bulletin, 28(6), 744-753.

Bravo, R., Matute, J., and Pina, J. M. 2012. 'Corporate social responsibility as a vehicle to reveal the corporate identity: A study focused on the websites of Spanish financial entities'. Journal of Business Ethics, 107(2), 129-146.

Brickson, S. L. 2005. 'Organizational identity orientation: Forging a link between organizational identity and organizations' relations with stakeholders'. Administrative Science Quarterly, 50, 576-609.

Calder, B. J., Phillips, L. W., and Tybout, A. M. 1982. 'The concept of external validity'. Journal of Consumer Research, 240-244.

Calder, B. J., Phillips, L. W., and Tybout, A. M. 1981. 'Designing research for application'. Journal of Consumer Research, 197-207.

Cho, S., and Hong, Y. 2009. 'Netizen's evaluations of corporate social responsibility: Content analysis of CSR news stories and online readers' comments'. Public Relations Review, 35(2), 147-149.

Clark, S. M., Gioia, D. A., Ketchen, D. J., and Thomas, J. B. 2010. 'Transitional identity as a facilitator of organizational identity change during a merger'. Administrative Science Quarterly, 55(3): 397-438. 
Clarkson, M. B. E. 1995. 'A stakeholder framework of analyzing and evaluation corporate social performance'. Academy of Management Review, 20(1), 92-117.

Collier, J., and Esteban, R. 2007. 'Corporate social responsibility and employee commitment'. Business ethics: A European review, 16(1), 19-33.

Crane, A., and Ruebottom, T. 2011. 'Stakeholder theory and social identity: Rethinking stakeholder identification'. Journal of Business Ethics, 102, 77-87.

Currás, R. 2009. 'Effects of perceived identity based on corporate social responsibility: The role of consumer identification with the company'. Corporate Reputation Review, 12, 177191.

Donaldson, T., and Preston, L. E. 1995. 'The stakeholder theory of the corporation: Concepts, evidence, and implications'. Academy of Management Review, 20(1), 65-91.

Du, S., Bhattacharya, C. B., and Sen, S. 2010. 'Maximizing business returns to corporate social responsibility (CSR): The role of CSR communication'. International Journal of Management Reviews, 12(1): 8-19.

Dutton, J.E., and Dukerich, J.M. 1991. 'Keeping An Eye on the Mirror: Image and Identity In Organizational Adaptation'. Academy of Management Journal, 34(3), 517-554.

Ellemers, N., van Knippenberg, A., de Vries, N., and Wilke, H. 1988. 'Social identification 
and permeability of group boundaries'. European Journal of Social Psychology, 18, 497-513.

Ellemers, N., Kortekaas, P., and Ouwerkerk, J. W. 1999. 'Self-categorisation, commitment to the group and group self-esteem as related but distinct aspects of social identity'. European Journal of Social Psychology, 29, 371-389.

Ellemers, N., Kingma, L., van de Burgt, J., and Barreto, M. 2011. 'Corporate social responsibility as a source of organizational morality, employee commitment and satisfaction'. Journal of Organizational Moral Psychology, 1(2), 97-124.

Ellen P.S., Webb, D.J., and Mohr L.A. 2006. 'Building Corporate Associations: Consumer Attributions for Corporate Socially Responsible Programs'. Journal of the Academy of Marketing Science. 34(2), 147-157.

Freeman, R. E. 1984. Strategic Management: A Stakeholder Approach. Massachusetts: Pitman Publishing.

Graafland, J., and van de Ven, B. 2006. 'Strategic and moral motivation for corporate social responsibility’. Journal of Corporate Citizenship, 22, 111-123.

Groves, K. S., and LaRocca, M. A. 2011. 'An empirical study of leader ethical values, transformational and transactional leadership, and follower attitudes toward corporate social responsibility'. Journal of Business Ethics, 103(4), 511-528.

Guest, G. A., Bunce, A., \& Johnson, L. 2006. How many interviews are enough? An 
experiment with data saturation and variability. Field Methods, 18: 59-82.

Hall, D. T., and Schneider, B. 1972. 'Correlates of organizational identification as a function of career pattern and organizational type'. Academy of Management Proceedings, 1,159-161.

Henson, R.K. 2001. 'Understanding internal consistency reliability estimates: A conceptual primer on coefficient alpha'. Measurement and Evaluation in Counseling and Development, $34(3), 177-189$.

Herrbach, O. and Mignonac, K., 2004. 'How Organizational Image Affects Employee Attitudes'. Human Resource Management Journal, 14(4), 76-88.

Johansen, T. S., and Nielsen, A. E. 2011. 'Strategic stakeholder dialogues: a discursive perspective on relationship building'. Corporate Communications: An International Journal, 16(3), 204-217.

Kim, Y., and Kim, S. Y. 2010. 'The influence of cultural values on perceptions of corporate social responsibility: Application of Hofstede's dimensions to Korean public relations practitioners'. Journal of Business Ethics, 91(4), 485-500.

Kramer, R. M. 1991. 'Intergroup Relations and Organizational Dilemmas. The role of categorization processes'. Research in Organizational Behavior, 13, 191-228.

Kuvaas, B. 2006. 'Work performance, affective commitment, and work motivation: the roles of pay administration and pay level'. Journal of Organizational Behavior, 27(3), 365-385. 
Lance, C.E., Butts, M.M., and Michels, L.C. 2006. 'The sources of four commonly reported cutoff criteria: What did they really say?'. Organizational Research Methods, 9 (2), 202-220.

Lapeyre, A. 2013. 'Le discours societal d'une enseigne de la grande distribution: effets de la legitimite de l'annonceur et de la credibilite du discours sur les consommateurs'. Revue Française du Marketing, (242).

Lee, E. M., Park, E-Y., and Lee, H. J. 2013. 'Employee perception of CSR activities: Its antecedents and consequences'. Journal of Business Research, 66(10), 1716-1724.

Mael, F., and Ashforth, B. E. 1992. 'Alumni and their alma mater: A partial test of the reformulated model of organizational identification'. Journal of organizational Behavior, 13(2), 103-123.

Maignan, I. 2001. 'Consumers' perceptions of corporate social responsibilities: A crosscultural comparison'. Journal of Business Ethics, 30(1), 57-72.

Margolish, J. D. and Walsh, J. P. 2003. 'Misery loves companies: Rethinking social initiatives by business'. Administrative Science Quarterly 48, 268-305.

McShane, L., and Cunningham, P. 2012. 'To thine own self be true? Employees' judgments of the authenticity of their organization's corporate ocial responsibility program'. Journal of Business Ethics, 108, 81-100 
Meyer J.P., Allen, N.J., and Smith, C.A., 1993. 'Commitment to organizations and occupations: Extension and test of a three-component concpetualization', Journal of Applied Psychology, 78(4), $538-551$

Morling, B., Kitayama, S., and Miyamoto, Y., 2002. 'Culturalpractices emphasize influence in the United States and adjustment in Japan', Personality and Social Psychology Bulletin 28(3), $311-323$.

Nunnally, J. 1978. Psychometric methods. New York: McGraw-Hill.

Rhoades, L., Eisenberger, R. and Armeli, S. 2001. 'Affective commitment to the organization: The contribution of perceived organizational support'. Journal of Applied Psychology 86(5): 825-836.

Podsakoff, P., MacKenzie, S., Lee, J., and Posdakoff, N. 2003. 'Common method biases in behavioral research: A critical review of the literature and recommended remedies'. Journal of Applied Psychology, 88, 879-903

Preacher, K. J., and Hayes, A. F. 2004. 'SPSS and SAS procedures for estimating indirect effects in simple mediation models'. Behavior Research Methods, Instruments, \& Computers, $36,717-731$.

Russell, D.W., and Russell, C.A. 2010. 'Here or there? Consumer reactions to corporate social responsibility initiatives: Egocentric tendencies and their moderators'. Marketing Letters, 21(1), 65-81. 
Sen, S., and Bhattacharya, C.B. 2001. 'Does doing good always lead to doing better? Consumer reactions to corporate social responsibility'. Journal of Marketing Research, $38(2), 225-243$.

Sen, S., Bhattacharya, C.B., and Korschun, D. 2006. 'The role of corporate social responsibility in strengthening multiple stakeholder relationships: A field experiment'. Journal of the Academy of Marketing Science, 2,158-166.

Scott, V.R., and Lane, S. R. 2001. 'A stakeholder approach to organizational identity'. Academy of Management Review, 25(1), 43-62.

Shore, L.M., Barksdale, K., and Shore, T.H., 1995. 'Managerial perceptions of employee commitment to the organization', Academy of Management Journal, 38(6), 1593-1615.

Story, J. and Neves, P. 2015. 'When corporate social responsibility (CSR) increases performance: exploring the role of intrinsic and extrinsic CSR attribution'. Business Ethics: A European Review, 24(2), 111-124.

Tajfel, H. (Ed.) 1978. Differentiation between social groups: Studies in the social psychology of intergroup relations. London: Academic Press.

Tajfel, H., and Turner, J. 1979. 'An integrative theory of intergroup conflict' In W. G. Austin \& S. Worchel (Eds.), The Social Psychology of Intergroup Relations: 33-48. Monterey, CA: Brooks/Cole. 
ter Hoeven, C. L., and Verhoeven, J. W. 2013. 'Sharing is caring: Corporate social responsibility awareness explaining the relationship of information flow with affective commitment'. Corporate Communications: An International Journal, 18(2), 264-279.

Tyler, T. R., and Blader, S. L. (Eds.). 2000. Cooperation in groups: Procedural justice, social identity, and behavioral engagement. Psychology Press.

Whetten, D.A. 2006. 'Albert and Whetten revisited: Strengthening the concept of organizational identity'. Journal of Management Inquiry, 15(3), 219-234.

Van Riel, C. B. M., and Balmer, J. M. T. 1997. 'Corporate identity: The concept, its management and measurement'. European Journal of Marketing, 31(5\&6), 340-355.

Waldman, D. A. and D. Siegel. 2008. 'Defining the Socially Responsible Leader'. The Leadership Quarterly, 19(1), 117-131.

Waldman, D. A., de Luque, M. S., Washburn, N., House, R. J., Adetoun, B., Barrasa, A., and Wilderom, C. P. 2006. 'Cultural and leadership predictors of corporate social responsibility values of top management: A GLOBE study of 15 countries'. Journal of International Business Studies, 37(6), 823-837.

Weick, K. E. 1995. Sensemaking in Organizations . Thousand Oaks, CA: Sage. 
Table 1. Pilot study results

\begin{tabular}{|c|c|c|c|c|}
\hline & Categories & Codes & $\%$ & Examples \\
\hline \multirow[t]{4}{*}{ CSR approach } & \multirow[t]{2}{*}{ Authentic } & $\begin{array}{l}\text { Stakeholder relations, } \\
\text { honesty }\end{array}$ & 36.36 & $\begin{array}{l}\text { CSR is based on a } \\
\text { client wellbeing, } \\
\text { done honestly and } \\
\text { with trust, employees } \\
\text { valued }\end{array}$ \\
\hline & & $\begin{array}{l}\text { Fair play, help } \\
\text { consistency }\end{array}$ & 18.15 & $\begin{array}{l}\text { Active and well- } \\
\text { thought CSR, } \\
\text { contribution to } \\
\text { society, done in co- } \\
\text { operation with others }\end{array}$ \\
\hline & \multirow[t]{2}{*}{ Instrumental } & $\begin{array}{l}\text { Benefits for the } \\
\text { company }\end{array}$ & 31.82 & $\begin{array}{l}\text { CSR is expected to } \\
\text { bring benefits such as } \\
\text { reputation, lack of } \\
\text { planned approach to } \\
\text { CSR }\end{array}$ \\
\hline & & $\begin{array}{l}\text { Profits, } \\
\text { quality }\end{array}$ & 13.64 & $\begin{array}{l}\text { CSR is driven by } \\
\text { profit seeking and } \\
\text { financial motives }\end{array}$ \\
\hline
\end{tabular}


Table 2 Means, standard deviations and correlations among variables

\begin{tabular}{|c|c|c|c|c|c|c|c|}
\hline & Mean & $\mathrm{SD}$ & 1 & 2 & 3 & 4 & 5 \\
\hline 1 Affective attachment to CSR & 20.78 & 4.13 & & & & & \\
\hline 2 Authentic CSR & 6.79 & 1.52 & $\begin{array}{l}.67 \\
(<.001)\end{array}$ & & & & \\
\hline 3 Instrumental CSR & 12.20 & 2.50 & $\begin{array}{l}.33 \\
(<.001)\end{array}$ & $\begin{array}{l}. .44 \\
(.001)\end{array}$ & & & \\
\hline 4 Individual identity orientation & .92 & .91 & $\begin{array}{l}.35 \\
(<.001)\end{array}$ & $\begin{array}{l}.46 \\
(<.001)\end{array}$ & $\begin{array}{l}.18 \\
(.046)\end{array}$ & & \\
\hline 5 Relational identity orientation & 1.26 & .99 & $\begin{array}{l}.07 \\
(.435)\end{array}$ & $\begin{array}{l}.04 \\
(.660)\end{array}$ & $\begin{array}{l}.10 \\
(.271)\end{array}$ & $\begin{array}{l}.47 \\
(<.001)\end{array}$ & \\
\hline 6 Collectivistic identity orientation & .69 & .88 & $\begin{array}{l}.43 \\
(<.001)\end{array}$ & $\begin{array}{l}.43 \\
(<.001)\end{array}$ & $\begin{array}{l}.29 \\
(.001)\end{array}$ & $\begin{array}{l}.37 \\
(<.001)\end{array}$ & $\begin{array}{l}.46 \\
(<.001)\end{array}$ \\
\hline
\end{tabular}


Table 3 Regression analyses

\begin{tabular}{|c|c|c|c|c|}
\hline Dependent variable & Predictors in the final model & Beta & $t$ & $p$ \\
\hline \multirow{6}{*}{$\begin{array}{l}\text { Instrumental CSR } \\
R^{2}=.12, F=5.28, p<.001\end{array}$} & Constant & & 19.75 & $<.001$ \\
\hline & Length of employment & .10 & 1.10 & .275 \\
\hline & Managerial responsibility & -.11 & -1.23 & .220 \\
\hline & Individual identity orientation & .063 & .666 & .507 \\
\hline & Relational identity orientation & -.076 & -.749 & .455 \\
\hline & Collective identity orientation & -.29 & -3.37 & .001 \\
\hline \multirow{6}{*}{$\begin{array}{l}\text { Authentic CSR } \\
R^{2}=.28, F=23.41, p<.001\end{array}$} & Constant & & 29.43 & $<.001$ \\
\hline & Length of employment & -.06 & -.80 & .427 \\
\hline & Managerial responsibility & -.02 & -.26 & .793 \\
\hline & Individual identity orientation & -.32 & -3.73 & $<.001$ \\
\hline & Relational identity orientation & .15 & .30 & .764 \\
\hline & Collective identity orientation & .31 & 3.67 & $<.001$ \\
\hline \multirow{6}{*}{$\begin{array}{l}\text { Affective attachment to CSR } \\
R^{2}=.21, F=16.07, p<.001\end{array}$} & Constant & & 30.43 & $<.001$ \\
\hline & Length of employment & -.03 & -.38 & .703 \\
\hline & Managerial responsibility & .02 & .28 & .779 \\
\hline & Individual identity orientation & -.18 & -2.04 & .044 \\
\hline & Relational identity orientation & -.19 & -.37 & .709 \\
\hline & Collective identity orientation & .35 & 3.86 & $<.001$ \\
\hline \multirow{5}{*}{$\begin{array}{l}\text { Affective attachment to CSR } \\
R^{2}=.44, F=92.65, p<.001\end{array}$} & Constant & & 6.79 & $<.001$ \\
\hline & Length of employment & -.01 & -.18 & .856 \\
\hline & Managerial responsibility & .07 & 1.01 & .313 \\
\hline & Authentic_CSR & .66 & 9.63 & $<.001$ \\
\hline & Instrumental_CSR & -.06 & -.75 & .453 \\
\hline
\end{tabular}


Table 4. Results of mediation analyses (dependent variable: Affective attachment to CSR)

\begin{tabular}{||l|l|c|r|r|r|r||}
\hline \multicolumn{1}{|c|}{ Predictor } & \multicolumn{1}{|c|}{ Mediator } & $\begin{array}{c}\text { Bootstrap } \\
95 \% C I\end{array}$ & $\beta_{Y X}$ & $\beta_{M X}$ & $\beta_{Y M(X)}$ & $\beta_{Y X(M)}$ \\
\hline $\begin{array}{l}\text { Individual identity } \\
\text { orientation }\end{array}$ & Instrumental & $-.55-.01$ & $\begin{array}{r}-1.67 \\
(<.001)\end{array}$ & $\begin{array}{r}0.47 \\
(.055)\end{array}$ & $\begin{array}{r}-0.45 \\
(.001)\end{array}$ & $\begin{array}{r}-1.46 \\
(<.001)\end{array}$ \\
\hline $\begin{array}{l}\text { Relational identity } \\
\text { Crientation }\end{array}$ & Instrumental & $-.44-.09$ & $\begin{array}{r}-0.29 \\
(.451)\end{array}$ & $\begin{array}{r}0.28 \\
(.225)\end{array}$ & $\begin{array}{r}-0.53 \\
(<.001)\end{array}$ & $\begin{array}{r}-0.14 \\
(.704)\end{array}$ \\
\hline $\begin{array}{l}\text { Collective identity } \\
\text { orientation }\end{array}$ & $\begin{array}{l}\text { Instrumental } \\
\text { CSR }\end{array}$ & $.02-.63$ & $\begin{array}{r}2.04 \\
(<.001)\end{array}$ & $\begin{array}{r}-0.84 \\
(<.001)\end{array}$ & $\begin{array}{r}-0.35 \\
(.010)\end{array}$ & $\begin{array}{r}1.75 \\
(<.001)\end{array}$ \\
\hline $\begin{array}{l}\text { Individual identity } \\
\text { orientation }\end{array}$ & Authentic CSR & $-1.95--.81$ & $\begin{array}{r}-1.68 \\
(<.001)\end{array}$ & $\begin{array}{r}-0.78 \\
(<.001)\end{array}$ & $\begin{array}{r}1.72 \\
(<.001)\end{array}$ & $\begin{array}{r}-0.34 \\
(.324)\end{array}$ \\
\hline $\begin{array}{l}\text { Relational identity } \\
\text { orientation }\end{array}$ & Authentic CSR & $-.34-.58$ & $\begin{array}{r}-0.29 \\
(.452)\end{array}$ & $\begin{array}{r}0.05 \\
(.733)\end{array}$ & $\begin{array}{r}1.82 \\
(<.001)\end{array}$ & $\begin{array}{r}-0.37 \\
(.188)\end{array}$ \\
\hline $\begin{array}{l}\text { Collective identity } \\
\text { orientation }\end{array}$ & Authentic CSR & $.77-1.72$ & $\begin{array}{r}2.03 \\
(<.001)\end{array}$ & $\begin{array}{r}0.74 \\
(<.001)\end{array}$ & $\begin{array}{r}1.60 \\
(<.001)\end{array}$ & $\begin{array}{r}0.84 \\
(.014)\end{array}$ \\
\hline
\end{tabular}

Bootstrap 95\% CI: 95\% bootstrap generated confidence intervals.

$\beta_{Y X}$ : beta for the direct effect of the predictor on the dependent variable;

$\beta_{M X}$ : beta for the direct effect of the predictor on the mediating variable;

$\beta_{Y M(X)}$ : beta for the direct effect of the mediator on the dependent variable, controlled for the predictor; $\beta_{Y X(M)}$ : beta for the indirect effect of the predictor on the dependent variable, controlled for the mediator. $P$ values for the betas are given in parentheses. 